\title{
Considerações sobre neonatos de baixo peso ao nascer
}

Graciella Melo de Araújo ${ }^{1}$, Martha Maria Macêdo Bezerra ${ }^{2}$;hércia Lucena Grangeiro Maranhão ${ }^{3}$

\begin{abstract}
Resumo: O presente trabalho tem por objetivo geral, caracterizar a prevalência de todos os nascimentos de baixo peso, ocorridos no Hospital e Maternidade São Lucas - Juazeiro do Norte/CE, entidade pública municipal, no período de junho a agosto/2012. A presente pesquisa excluiu os natimortos. Foram acompanhadas 904 mães, durante os meses de junho, julho e agosto do ano 2012, o que representa a totalidade dos partos acontecidos neste período, onde desses, passaram a objeto do presente estudo, 67 recém-nascidos de baixo peso, sendo 26 nascidos no mês de junho, 14 no mês de julho e 27 no mês de agosto/2012. As informações foram colhidas à partir de revisão dos prontuários do Hospital, das Declarações de Nascidos Vivos - MS, de informações contidas nas Fichas Perinatais utilizadas no Programa de Saúde da Família e de questionário (instrumento de coleta de dados) elaborado para a finalidade do trabalho. Os resultados obtidos revelam que a taxa de recém-nascidos com baixo peso ao nascer ainda é muito alta e que a mortalidade de bebês apresentou-se muito significativa entre as mães mais jovens, principalmente na faixa de 13 a 16 anos(60\%) e nas faixas de 17 a 20 e 21 a 24 foram de $30 \%$ e $26 \%$ respectivamente, índices considerados altos pela Organização Mundial de Saúde - OMS. Crianças pertencentes às famílias de baixo nível sócio-econômico-cultural, que é o caso da maioria das mães pesquisadas (11\% nunca estudou e 71,64\% não chegou a concluir os estudos de $1^{\circ}$. grau; $89,55 \%$ são trabalhadoras do lar e $56,71 \%$ são solteiras ou não tem um companheiro estável), estão expostas a riscos biológicos e sociais, necessitando assim de maior atenção dos órgãos governamentais na assistência social e de saúde. Este estudo constatou que uma melhoria da atenção primária de saúde, por ocasião do pré-natal, contribuiu sobremaneira para a melhoria das condições de nascimento, sobrevivência e desenvolvimento da população infantil.
\end{abstract}

Palavras-chave: Neonatos, Baixo Peso, Recém-nascidos.

\section{Considerations about Low Birthweight in Newborns}

\begin{abstract}
The present study has the objective to characterize the prevalence of all low birth weight occurred at Hospital São Lucas - Juazeiro / CE, municipal public entity, in the period of June-August / 2012. This study excluded stillbirths. 904 mothers were followed during the months of June, July and August of the year 2012, which represents all the births that occurred in this period, where these, the object of this study, 67 newborns underweight, with 26 births in June, 14 in July and 27 in August / 2012. The information was collected from a review of the medical records from Hospital of Live Birth Certificates - MS, the information contained in the Sheets used in Perinatal Health Program of Family and the questionnaire (data collection instrument) prepared for the purpose of the study. The results show that the rate of newborns with low birth weight is still too high and that the mortality of infants presented very significant among younger mothers, mainly in the range of 13-16 years $(60 \%)$ and in the 17-20 and 2124 were 30\% and 26\% respectively, rates considered high by the World Health Organization - OMS. Children belonging to families of low socio-economic-cultural level, which is the case for most mothers surveyed $\left(11 \%\right.$ and $71.64 \%$ never studied did not actually complete the first studies ${ }^{\circ}$. $89.55 \%$ are household and $56.71 \%$ are single or do not have a stable mate), are exposed to biological and social risks, thus requiring more attention from government bodies in social care and health. This study found that improved primary health care, during the prenatal, contributed greatly to the improvement of birth, survival and development of the child population.
\end{abstract}

Keywords: Newborns, Low Weight Newborns

\footnotetext{
Enfermeira, Bacharel pela Universidade Regional do Cariri - URCA (2014). Especialista em Estratégia de Saúde da Família pela Universidade Estadual Vale do Acaraú - UVA. Residência em Saúde da Família e da Comunidade pela Escola de Saúde Pública do Ceará. Email: graciellamelo_@hotmail.com;

${ }^{2}$ Programa de Pós-Graduação da Faculdade de Medicina do ABC - São Paulo - SP. E-mail: dblf@ig.com.br;

${ }^{3}$ Psicóloga , Graduada pela Faculdade de Ciências Humanas de Recife - ESUDA, Especialista em Gestão do Trabalho e da Educação na Saúde, pela Escola de Saúde Pública do Estado do Ceará . Aluna do Programa de Pós- Graduação da Faculdade de Medicina do ABC , do curso de Mestrado em Ciências da Saúde. E-mail: thercia@leaosampaio.edu.br
} 


\section{Introdução}

Diversos são os estudos que indicam a condição do nascimento, considerando o peso das crianças ao nascer. Na literatura nacional e internacional, uma considerável quantidade de estudos demonstram a importância do peso ao nascer, com ênfase específica no déficit de peso no momento do nascimento. Estes estudos têm demonstrado a relevante participação do baixo peso ao nascer, com a morbidade e a mortalidade infantil, em especial a perinatal, sendo considerado por muitos autores, como um predecessor da mortalidade na infância.

Por conta de seu grau de participação na mortalidade entre os menores de um ano, tem sido considerado como um indicador de saúde e de avaliação de programas assistenciais na área maternoinfantil.

Os recém-nascidos de baixo peso e prematuros, constituem um grupo de risco pela sua maior morbimortalidade, sendo, na maioria das vezes, a mortalidade dessas crianças dependentes de suas condições ao nascer e dos cuidados subsequentes.

A Organização Mundial de Saúde considera prematuro aquele que nasce antes de completar 38 semanas de gestação e de baixo peso, aquele com menos de $2500 \mathrm{~g}$, independentemente do tempo de gestação (OMS, 1983).

Os agravos à saúde têm sido estudados sob vários enfoques, sendo cada vez maior a preocupação com os fatores de risco. Novas abordagens na epidemiologia trouxeram entendimentos dos problemas de saúde infantil, demonstrando a associação entre a morbimortalidade, saneamento básico, estado nutricional, educação da mãe, situação sócio-econômica, oferta de serviços de saúde, dentre outros fatores correlacionados entre si. Conhecer esses fatores de risco a que estas crianças estão expostas e os que desencadearam a prematuridade e o baixo peso ao nascer, as dificuldades vivenciadas em situações precárias de vida, assim como os fatores protetores para as famílias em situação desfavorável, é de extrema importância para a atuação dos profissionais de saúde.

A ocorrência do baixo peso ao nascer é considerado um problema de saúde pública para muitos países.

É consenso o risco de nascer com baixo peso $(<2500 \mathrm{~g})$, tornando-se parâmetro para avaliação das condições de vida de uma criança e sua genitora como indicador de saúde desta população no contexto bio-psico-social. 


\section{O recém nascido de baixo peso para a idade gestacional}

Recém nascido de baixo peso para a idade gestacional (RNPIG) é definido, segundo o critério de Battaglia e Lubchenco(1967), como sendo aquele cujo peso de nascimento se situa abaixo do percentil 10, para a sua idade gestacional, baseado em uma curva de crescimento intra-uterino (CIU).

Existem outros critérios que têm sido empregados para o diagnóstico da condicão de Pequeno para a Idade Gestacional - PIG, tais como o de Gruenwald, que considerou como PIG aqueles RN com peso de nascimento inferior a dois desvios padrão da média (correspondente aproximadamente ao percentil 3), ou de Miller e Hassaneim, que recomendam como limite o percentil 5.

É importante frisar que o RNPIG não pode ser livremente designado como portador de retardo de crescimento intra-uterino (RCIU), pois para isso precisaria haver pelo menos duas mensurações ao longo do período de crescimento fetal, nem a principio como desnutrido, porque o PIG poderá ser apenas geneticamente pequeno, mas normal. Por outro lado, recém-nascidos com pesos que os coloca, na curva ao nascer, como de crescimento adequado poderão na verdade ter sofrido um retardo de crescimento e seu peso acabou sofrendo uma restrição, de difícil diagnóstico, ao longo da gestação.

A definição precisa de retardo de crescimento fetal ou de desnutrição fetal é, por sua vez, difícil. Faltam ainda meios clínicos e laboratoriais efetivos para o diagnóstico neonatal, embora o estudo morfométrico fetal ao ultra-som e o estudo da circulação materna e fetal pelo Dopller forneçam importantes dados nesse sentido.

Segundo Ramos (2000, p.153), os dados apresentados com características físicas e biológicas destes RN, geralmente, derivam do estudo de RNPIG, cujo diagnóstico é imediato pela consulta à curva de Crescimento Intra Uterino - CIU. Muitas das categorias de PIG já são, porém, bem estudadas na fase fetal, com obtenção dos dados que ilustram o prejuízo ou a restrição ao CIU e suas causas.

\footnotetext{
Muito provavelmente, um Recém-nascido pequeno para a idade gestacional (RNPIG), que esteja abaixo de percentil 3, pode ser considerado como portador de retardo significante, ou mesmo intenso, do crescimento. Presentemente,, tem sido considerado, embora não ainda utilizado, o termo "restrição", em substituição a "retardo" do crescimento. (RAMOS, 2000, p.153).
}

\section{Incidência}

De acordo com os autores, em países desenvolvidos cerca de um terço dos recém-nascidos de baixo peso (RNBP) é, na verdade de termo, pequeno para a idade gestacional; já nos países em desenvolvimento esta proporção é bem maior, podendo atingir 75\% do total de RNBP. 
Dados da Organização Mundial da Saúde (1983), indicavam haver 5,5\% dos RNBP nos países desenvolvidos, contra $18 \%$ nos países em desenvolvimento. Destes, $33 \%$ eram pequenos para a idade gestacional (PIG), nos países desenvolvidos, contra 75\% nos países em desenvolvimento. Já os prétermo adequados para a idade gestacional (PTA-AIG), representaram cerca de 66\% dos RNBP nos países desenvolvidos, contra $25 \%$ nos países em desenvolvimento.

Nesse contexto ,uma análise , feita no berçário anexo á maternidade do Hospital das Clinicas da FMUSP , mostrou que ,em 1250 nascidos vivos num total de 12,3\% de RNPIG, dos quais 3,4\% eram pré-termo e os restantes $8,9 \%$ de termo (e alguns raros pós-termo). (Ramos, Costa Vaz e Callil: 2000, p.153-154).

A análise destes resultados revelam diferenças entre os números citados e aqueles obtido nos países em desenvolvimento; este fato se deve , provavelmente, às peculiaridades do nosso meio, para o qual é triada uma população de altíssimo risco, com incidência elevada de interrupção precoce das gestações.

\section{Influências diversas no retardo do crescimento do feto}

Diferentes condições influenciam no retardo de crescimento do feto . É necessário acentuar, porém, que na maior parte das vezes os mecanismo fisiopatológicos que levam ao retardo de crescimento, nas condições mencionadas, não são bem compreendidos. Mesmo tendo em mente essas restrições, algumas considerações sobre a etiopatogenia do retardo de crescimento intra-uterino(RCIU) merecem comentários, como se fará a seguir.

a) Influências sócio-culturais:

Quando se tenta classificar um recém-nascido ou compara seu padrão de crescimento intrauterino com outros conhecidos, é importante valorizar os fatores clínicos ou populacionais. Ainda que se saiba que a influência dos fatores socioeconômicos é decisiva, e que ela provavelmente responde por muitas diferenças populacionais, a influência dos fatores étnicos, no momento, não deve ser descartada.

Se um recém-nascido de baixo peso proveniente de país em desenvolvimento for analisado dentro de uma curva de crescimento intre-uterino de país desenvolvido e de população privilegiada, maiores serão, em geral, as chances de ser considerado pequeno para a idade gestacional.

Segundo Ramos (2000, p.154), nos Estados Unidos da América do Norte, por exemplo, recém-nascidos afro-americanos são menores do que hispânicos e asiáticos, vivendo em condições socioeconômicas semelhantes. 
b) Fatores inerentes ao feto:

Fatores inerentes ao feto podem influir no seu crescimento. Exemplos incluem casos de baixa estatura genética, infecções congênitas diversas e alguns erros inatos do metabolismo. A maioria dos problemas fetais que resulta em alterações do crescimento produz retardos precoces e, portanto, "proporcionados" de crescimento, ou seja, com diminuição de peso, estatura e, em algumas situações, de perímetro cefálico. Segundo o autor:

\begin{abstract}
As anomalias congênitas freqüentemente transcorrem com diminuição do peso. Em revisão do British Perinatal Mortality Survey, a média para o peso de nascimento de malformados foi de $1.001 \mathrm{a} 1.500 \mathrm{~g}$, enquanto a média do tempo de gestação foi de 38-39 semanas. As seguintes prevalências de anomalias no grupo total de PIG podem ser citadas: Rumbolz et al. $=10,5 \%$; Scot; Usher $=11 \%$ e Van den Berg; Yerushalmy $=16,5 \%$. Lembramos que, para a população geral de RN, a proporção de malformados varia, sendo em geral cerca de $2 \%$; em São Paulo, um estudo prospectivo mostrou 1,63\% (RAMOS e col: 1981, p.19).
\end{abstract}

O feto masculino cresce mais que o feminino, especialmente após 32-34 semanas o de termo é em geral $0,9 \mathrm{~cm}$ mais longo, $150 \mathrm{~g}$ mais pesado e possui perímetro cefálico maior.

c)Alterações do apoio (ou suporte) do crescimento fetal:

A influência das condições da mãe:

Segundo Ramos e col.: 2000, p.154),

\begin{abstract}
A influência das condições materna sobre o CIU pode ser ilustrada de várias maneiras, como os estudos de cruzamentos de animais ,planejado para mostra o impacto do tamanho da mãe sobre o CIU de fetos com o mesmo patrimônio genético . Dessa experiências se conclui que o organismo materno exerce uma regulação importante do tamanho atingido pelo feto , independente do genótipo.
\end{abstract}

A esse respeito, vale citar estudo clinico que mostra um coeficiente de correlação de pesos de nascimento de meio-irmãos maternos de 0,581, para apenas 0,102 para meio-irmãos paternos (como termo de comparação, irmãos sucessivos tinham coeficiente de correlação igual a 0,523). Polani (1974), trabalhando com dados de Karn, Penrose e outros, acha que o peso do feto recebe as seguintes influências relativas: $38 \%$ genéticas e $62 \%$ do ambiente; incluindo o organismo materno. Este último seria responsável por metade das influências ambientais, a outra metade sendo geralmente desconhecida.

A pequena estatura materna tem sido, tradicionalmente relacionada com o nascimento de fetos de menor peso ao nascimento. Entretanto, o Projeto Perinatal da Universidade de Columbia, 
publicado em 1973, mostrou que, quando a estatura é analisada dentro de um determinado grupo de peso pré-concepcional, não guarda relação constante com o peso do recém-nascido.

Existem estudos, porém, valorizando muito a influência da estatura materna dentro de cada idade gestacional. Tal fato sugere a importância de se usar um fator de correção para a estatura materna na aferição de curvas de CIU, como já foi feito em pequeno número de estudos.

A relação desta variável com a paridade é por vezes um fator de confusão. É importante destacar-se o que ocorre com filhos de adolescentes. O número de recém-nascidos de baixo peso dessas mães é maior que o da população geral e parece que as crianças subsequentes de mães que iniciam sua vida reprodutiva antes dos 20 anos também têm maior incidência de baixo peso.

Parece certo, porém, que mães na segunda parte da adolescência, ou seja, com mais de 16 anos, se adequadamente cuidadas, terão filhos de peso adequado. (Spallici, 2000)

O fumo durante a gravidez resulta em diminuição do peso fetal (cerca de $170 \mathrm{~g}$ em média, se mais de dez cigarros por dia; cerca de $300 \mathrm{~g}$ se mais de 15). Possíveis mecanismos desse efeito são a hipóxia fetal decorrente por catecolaminas secretadas em resposta à nicotina, bem como alterações causadas pelo monóxido de carbono e cianeto no transporte de oxigênio materno-fetal. É muito pouco conhecida a interação e a importância relativa dos diversos fatores. Há evidencias de que o abandono do fumo no terceiro trimestre pode impedir que se manifestem os efeitos sobre o peso ao nascer. Os efeitos do fumo parecem não estar significativamente ligados à nutrição materna. Assim, suplementação alimentar pode modificar, mas não suprimir os efeitos atribuíveis ao fumo (Ramos, Costa Vaz e Callil: 2000, p.155).

O uso de narcóticos pela mãe se acompanha de nascimento de crianças de peso deficiente, ao mesmo tempo que parece protege-las da incidência de doenças de membranas hialinas e de hiperbilirrubinemia. A ingestão de álcool, possivelmente mesmo em quantidades socialmente usuais, pode acompanhar-se de problemas sérios de crescimento em peso, estatura e perímetro cefálico, bem com de elevadas quantidades de retardamento mental e malformações, como, por exemplo, membros desproporcionalmente curtos em relação ao tronco. Acredita-se que essas deficiências reflitam o agravo à proliferação celular dependente dos níveis de álcool. Hormônio de crescimento, cortisol e gonadotrofinas têm-se revelado normais nesses pacientes. A suscetibilidade ao álcool varia segundo indivíduos e população, sendo possível que isso explique diferenças de incidência de efeito de álcool no feto. Não está bem estabelecido se é o próprio etanol o agente nocivo ou se algum metabólito, por exemplo, o acetaldeído. Não se conhece também a quantia mínima diária "perigosa", havendo evidências de que a ingestão de $89 \mathrm{ml}$ de álcool (cerca de seis “drinks") ou mais por dia, constitui risco muito importante e que o alcoolismo crônico, em geral, pode resultar em $50 \%$ de sérios problemas fetais. No momento, não é possível indicar nível de consumo absolutamente seguro de ingestão. O retardo no crescimento intra-uterino (RCIU) conseqüente ao "alcoolismo fetal" geralmente não 
responde aos bons cuidados pós-natais, não havendo retomada de crescimento. (Ramos, Costa Vaz e Callil: 2000, p.155).

Muito se tem escrito sobre as relações entre o estado nutricional da mãe e a qualidade do crescimento fetal. Essa influência, apesar de muito estudada, principalmente em relação ao peso de nascimento, em estudos clínicos, em experimentação animal e em trabalhos de campo, ainda não é perfeitamente compreendida em seus diversos aspectos no que se refere à espécie humana.

Algumas relações entre condição nutricional materna e qualidade do CIU expresso pelo peso ao nascer, que aparentemente podem ser aceitas,segundo Ramos (2000, p.155-156), são comentadas a seguir:

a) A condição nutricional materna pré-concepcional (incluindo a história nutricional de toda a vida da mãe) aparentemente se reflete no CIU.

b) As condições de nutrição durante a gestação, especialmente durante o terceiro trimestre, também se refletem diretamente no CIU.

Durante o primeiro trimestre a influencia da nutrição materna sobre o crescimento fetal aparentemente é mínima, dadas as necessidades pequenas do embrião/feto. Porém, um ganho de peso insuficiente desde o início do segundo trimestre da gestação.

O conhecimento do índice de massa corpórea baixo pode necessitar um ganho de peso gestacional de 12,5 a $18 \mathrm{~kg}$, enquanto uma gestante obesa pode necessitar um ganho de peso bem menor, de cerca de $6 \mathrm{~kg}$, para evitar uma restrição de crescimento fetal.

c) As duas condições mencionadas (pré e intragestação) são geralmente aditivas em sua influência sobre o CIU.

d) É possível que os tipos de agravo nutricional ocorrendo na gestação, ou seja, esporádico, novamente vem à tona a importância do trimestre em que ocorre e de sua duração.

e) O emprego de suplementação da dieta materna durante a gravidez tem resultado em incrementos de peso no RN (Guatemala, 1975; Colômbia, 1979; Formosa, 1980 e 1984) ou ausência de incremento (Nova Iorque, 1980) Os incrementos médios encontrados são em geral pequenos e, ao que parece, pouco representativos do ponto de vista prático, embora no estudo da Guatemala se tenha diminuído significativamente o número de RN de baixo peso. Considera-se a oferta de 20.000 calorias a mais, por gestação, capaz de reduzir o número de $\mathrm{RN}$ de baixo peso e, segundo Kliegman (1997), que a cada 10.000 calorias suplementadas, acima da dieta habitual, podem aumentar 29g no peso fetal. A suplementação calórica correlaciona-se melhor com ganho de peso, ao passo que suplementação protéica pode inclusive ter efeitos nocivos sobre o desenvolvimento fetal. Aparentemente, a suplementação só se aplica quando há um risco nutricional bem definido na população-alvo. Por exemplo, gestantes de Gâmbia, em períodos de baixa produção de alimentos, receberam suplementação calórica, com aumento de 224 g no peso 
ao nascer e redução da incidência de baixo peso de $28 \%$ para $5 \%$. Parece existir um limiar de ingestão materna de calorias e/ou proteínas abaixo do qual o feto não cresceria de acordo com todo seu potencial. Estes limiares seriam cerca de 1.800 a 2.000 cal/dia, segundo Naismith (1981), e de $50 \mathrm{~g}$ de proteína/dia, segundo Widdwson(1981). Acima de determinado limiar de ingestão proteico-calórica, que poderia ser o acima indicado, provavelmente não se deve esperar efeitos intensificáveis da condição nutricional materna sobre o CIU. Assim, como acentuam Rush e cols., acima de um certo limiar, grande parte da associação da dieta materna com o peso do RN provavelmente não é causal.

f) A época de ocorrência de um agravo nutricional na gestação pode refletir-se em tipos de retardo de crescimento fetal. Se o agravo ocorrer no fim da gestação, o perímetro cefálico e a estatura serão respeitadas; se o agravo for precoce, antes do pico de crescimento em comprimento e da cabeça, este estará prejudicado. No primeiro caso haverá o retardo de crescimento dito assimétrico ou desproporcionado; no segundo caso será o simétrico ou proporcionado, havendo normas de transição. No tipo assimétrico, o índice ponderal de Rohrer é baixo, sendo geralmente normal no simétrico (v. classificação adiante). Algumas investigações têm mostrado que as mães de RNPIG com índice ponderal adequado ("proporcionados" ou "simétricos") têm estatura e perímetro cefálico menores que as mães de RN com índice ponderal baixo ("assimétricos"). Esse dado sugere um agravo nutricional de longa duração mais freqüente nas mães de $\mathrm{RN}$ com retardo "proporcionado". É importante distinguir-se entre esses tipos de retardo de CIU, devido ao pior prognóstico somático e neuromotor do grupo "simétrico".

g) Recém-nascidos pequenos do ponto de vista "adaptativo": Tem-se discutido muito sobre a possibilidade de que o crescimento fetal restrito ou retardado possa ser, em algumas situações, um fenômeno "adaptativo", ou seja, em condições maternas desfavoráveis, haveria o nascimento de criança "adaptadas " para as condições de nutrição e de vida da mãe do meio em que vivem. Este tipo de abordagem menciona também a possibilidade desse tipo de "adaptação" visar melhores condições do ponto de vista do parto propriamente dito. Uma corrente de pensamento que foi defendida por Dobbing (sd), diz, ao contrário, que não se deve aceitar como fisiológica qualquer restrição ao crescimento fetal; o feto deve ser sempre apoiado ao máximo de suas possibilidades individuais. Hoje, parece importante, lembrarmos que fetos de peso pequeno do ponto de vista "adaptativos", se realmente assim considerados, deverão ser motivos de preocupação. Isto porque estudos recentes mostram que o suprimento restrito de nutrientes ao feto pode conduzir provavelmente como adaptação a essas condições, a alterações permanentes no metabolismo e na fisiologia fetais. Essas alterações acredita-se, aumentam a probabilidade de instalação na vida futura de problemas como diabetes não insulino-dependente, hipertensão de 
doenças coronarianas. São comentados mais adiante, em "prognóstico e evolução do RNPIG”(Rodrigues, 1991).

\section{Classificacando os Recém-nascidos com baixo peso ao nascer}

O recém-nascido pequeno para a idade gestacional pode ser pré-termo, de termo ou pós-termo, segundo sua idade gestacional seja menor que 37 semanas, entre 37 e 42 ou maior que 42 semanas, respectivamente; suas características físicas e seu prognóstico poderão diferir de acordo com essas categorias.

Quanto ao grau de retardo de crescimento e, portanto , quanto à localização do recém-nascido nas curvas de CIU, podemos considerar dois grupos de recém-nascido pequeno para a idade gestacional: aqueles que estão situados entre os percentis 10 e 3 da curva e aqueles portadores de desvio maior da mediana, situados abaixo do percentil 3. Esta classificação nos auxilia a prever, com razoável margem de segurança, qual será o ritmo de crescimento imediato e remoto de determinado recém-nascido, bem como o provável tempo de permanência na unidade neonatal.

A classificação de Lins e Evans (1984) procura relacionar a fase do crescimento fetal comprometida à etiologia do retardo, ao quadro clínico associado. São os seguintes tipos considerados:

Tipo I (Simétrico) - é aquele em que o agente atua na fase precoce da gravidez, causando prejuízo ao processo de crescimento por hiperplasias; origina-se assim um feto e recém -nascido com reduções proporcionadas de peso, comprimento e perímetro cefálico. Os agentes mais encontrados são as infecções congênitas, as cromossopatias, certas drogas e radiações ionizantes;

Tipo II (Extrínseco) - é aquela em que se admite a expressão do agente preponderantemente $\mathrm{n}$ terceiro trimestre da gestação, fase correspondente ao crescimento por hipertrofia, ou seja, o crescimento celular, diferentemente da importante multiplicação celular que caracteriza o período embrionário. Esses recém-nascidos, freqüentemente tem seu comprimento (que tem seu ápice de crescimento na $20^{\mathrm{a}}$ semana) respeitados ou pouco afetado e o perímetro cefálico em geral, conservados. Apresentam portanto, o índice ponderal de Roher diminuído, diferentemente dos retardos do tipo simétrico;

Tipo III (Assimétrico) - é o tipo mais freqüentemente encontrado, devido geralmente à insuficiência das funções placentárias, mas podendo ser devido a fatores fetais. Tem prognóstico a médio e longo prazo melhor do que o retardo tipo I.

Acredita-se que o tipo intermediário é devido à ação nociva do segundo trimestre, havendo, em geral, algum comprometimento de comprimento e perímetro cefálico, embora mais leve do que no tipo I. Aceita-se a desnutrição, efeito de fármacos e fumo como agentes. 


\section{O Recém-nascido pequeno para a Idade Gestacional e suas características Físicas e fisiológicas}

As características clínicas e fisiológicas do recém-nascido pequeno para a idade gestacional (RNPIG) não podem ser facilmente resumidas. Como o universo dos PIG não é homogêneo, sendo muitas as causas de deficiência ponderal ao nascimento, é compreensível que essas causas impliquem em modificações das características do recém-nascido. É também lógico que um RNPIG cujo peso se situe muito próximo do percentil 10 apresente características próximas de um recém-nascido "adequado" e , por sua vez, diferente das de um situado abaixo do percentil 3. As mencionadas diferenças muito provavelmente também poderão influir no prognóstico a longo prazo desses recémnascidos.

Ainda assim, pode-se tentar esquematizar algumas características gerais do PIG, como se fará a seguir.

Mesmo se excluir casos especiais, como os recém-nascidos com cromossomopatia ou portadores de infecção congênita, a heterogeneidade dentro do grupo dos RNPIG, permanece. Ainda assim, é possível reconhecer características físicas freqüentemente encontradas neste grupo, a saber: cabeça relativamente grande em relação ao resto do corpo; fontanela bregmática grande; extremidades com pobreza de tecido celular subcutâneo; mãos e rosto com sugestão de "envelhecimento" (em oposição ao PT adequado); cordão umbilical pode parecer mais delgado que habitual; diminuição da espessura da prega cutânea; diminuição da circunferência da coxa e do braço.

$\mathrm{O}$ índice ponderal, bem como os vários perímetros e a espessura da prega cutânea são provavelmente testemunhas das alterações preferenciais do crescimento das partes moles, massa muscular e tecido adiposo durante a vida fetal e, assim, comportam-se diferentemente nas várias categorias de retardo no crescimento intra-uterino ou de idade gestacional. O mesmo pode ser esperado de muitas das características físicas acima mencionadas.

Restrição ao crescimento intra-uterino conseqüente a insuficiência placentária geralmente reduz o peso de nascimento mais do que o comprimento.

Como já foi acentuado, o retardo ou restrição do crescimento intra-uterino é o resultado de um desvio do potencial genético de crescimento, que poderá resultar ou não em um recém-nascido pequeno para a idade gestacional. O peso considerado ideal, que poderá ser modificado por fatores extrínsecos com ação sobre o feto, é potencialmente predileto pelo estudo ultra-sonográfico antropométrico e biométrico do feto no segundo trimestre. Comparando-se esses índices (peso, perímetro cefálico, circunferências abdominal e de coxa) com os obtidos ao nascimento, obter-se-á um escore que informa que grau de retardo eventualmente terá ocorrido. Este procedimento procura 
detectar retardo no crescimento intra-uterino, sendo que o recém-nascido assim nomeado poderá ou não ser pequeno para a idade gestacional.

As características fisiológicas do RNPIG possivelmente podem variar de acordo com o tipo de retardo de crescimento presente (nos quais variam as quantidades relativas de gordura, músculo e esqueleto) ou, ainda, segundo a deficiência ponderal apresentada pelo recém-nascido: se sua posição na curva for apenas ligeiramente inferior ao percentil 10, muito provavelmente certos problemas(por exemplo, a hipoglicemia neonatal) serão diversos dos de um PIG que se situa abaixo do percentil 3. A idade gestacional do RN considerado, também deve ser levada em conta: um pequeno para a idade gestacional(PIG) de termo pode diferir muito de um PIG pós-termo, principalmente se a prematuridade for extrema, caso em que as características da imaturidade serão mais marcantes em relação às dependentes do retardo de crescimento intra-uterino. O recém nascido de baixo peso póstermo (eventualmente pouco freqüente) em geral é PIG e suas características poderão ser diversas dos anteriores.

Embora todas as noções citadas sejam teoricamente corretas, na prática raramente se consegue identificar ou quantificar as características as características fisiológicas próprias de cada um dos recém-nascidos pequenos para a idade gestacional; em geral, referem-se aos "de termo pequeno para a idade gestacional".

$\mathrm{Na}$ presença de retardo na curva intra-uterina a mortalidade perinatal é de 5 a 20 vezes a dos de crescimento adequado. As mortes intra-uterinas ocorrem principalmente entre 38 e 42 semanas de gestação, período em que um cuidado perinatal efetivo pode evitar muitas mortes fetais. A asfixia perinatal é o problema mais sério dos recém-nascidos pequenos para a idade gestacional ao nascimento. Asfixia fetal aguda, bem como hipóxia crônica em muitos casos participam do quadro. É possível encontrar múltiplas manifestações da asfixia perinatal, não sendo raros, nos casos mais graves, a perfuração intestinal e necrose tubular aguda. Aspiração meconial é comum, acompanhada freqüentemente de síndrome de ar extrapulmonar.

\section{O recém-nascido pequeno para a Idade Gestacional e seus mecanismos de defesa}

Geralmente, o pequeno para a idade gestacional perde menos de 5\% de seu peso, ao passo que o TPIG perde mais de $5 \%$ a $10 \%$.

A esse respeito, vale salientar que a "perda de peso fisiológica" deve ser respeitada, pois é provavelmente um marco da passagem do estado hidroeletrolítico fetal para o neonatal. A água intracelular e o volume plasmático são especialmente aumentados no nascimento, particularmente nos 
fetos de crescimento mais retardado, com adaptações rápidas nas primeiras quatro a seis horas de vida. A água total e a extracelular se corrigem de maneira mais lenta.

$\mathrm{Na}$ vigência de insuficiência placentária, a capacidade de dispersão de calor do feto é insuficiente, o que pode fazer com que estes recém nascidos cheguem com temperatura elevada.

O recém-nascido pequeno para a idade gestacional tem, porém, menor envoltório de gordura, portanto menos isolamento térmico. Sua faixa de termoneutralidade é mais estreita que a de recémnascido de termo com peso adequado. Comparados com recém-nascido de menor idade gestacional e de mesmo peso, têm resistência maior devido ao maior tono muscular em flexão e à maior produção de calor quando em repouso. Isto mostra que a gordura marrom, envolvida na produção de calor, não está sempre diminuída no recém-nascido pequeno para a idade gestacional ou em razão de retardo do crescimento intra-uterino.

A adaptação perinatal deste metabolismo está, freqüentemente, prejudicada, tornando a hipoglicemia um achado freqüente e importante. Alguns fatores sabidamente contribuem para essa hipoglicemia, no recém-nascido pequeno para a idade gestacional(RNPIG).

a. Existe diminuída gliconeogênese protéica, com aumento dos níveis plasmáticos de alanina; essa diminuição da gliconeogênese poderia depender da diminuição da enzima fosfoenolpiruvatocarboxiquinase ou de bloqueio em nível de hexose 1-6 difosfato. No RNPIG hipoglicêmico existe elevado nível de lactato, além de alanina, sugerindo que há disponibilidade de substrato, sendo deficiente a gliconeogênese devido realmente a problemas de enzimas ou co-fatores. Os RNPIG não hipoglicêmicos mostram índices de gliconeogênese a partir de alanina aos de recém-nascido de peso adequado para a idade, também não hipoglicêmicos;

b. Diminuição das reservas de glicogênio hepático;

c. Existe uma desproporção entre o tamanho do cérebro (consumidor de glicose) e do fígado (produtor de glicose), nos RNPIG, presumivelmente mais acentuada nos RNPIG do tipo "desproporcionado";

d. Em muitos RNPIG a hipoglicemia não provoca uma resposta adequada de produção de catecolaminas;

e. A hipoglicemia do RNPIG usualmente não responde à ministração de glucagon. Tem sido demonstrada uma correlação da glicemia com o índice ponderais nestes recém-nascido; hipoglicemia é mais freqüente com índices ponderais mais baixos (ou seja, com retardo de crescimento "assimétrico").

Além dessas características, vale lembrar que influi no comportamento da glicemia neonatal a lenta resposta insulínica à administração de glicose, possivelmente participando na hiperglicemia 
iatrogênica não rara nessas crianças. Em alguns pequenos para a idade gestacional estudados, porém, observou-se hiperinsulismo ((Ramos, Costa Vaz e Callil: 2000, p.159).

A existência de um estado catabólico protéico e de uma baixa reserva calórica aos nascimentos nos pequenos para a idade gestacional é sugerida pelos níveis plasmáticos altos de amônia, uréia e ácido úrico. Um crescimento fetal retardado seguido por rápida melhora de ritmo de crescimento é sugerido pelo aumento da relação hidroxiprolina-creatinina na urina, nos primeiros dias, e da excreção urinária de glicosaminoglican.

Sabe-se que no sangue fetal, em condições normais, há níveis de nitrogênio alfaamínico superiores aos maternos e que a captação placentária de aminoácidos não depende dos níveis maternos, estando provavelmente na dependência direta do fluxo sangüíneo útero placentário. As maiores concentrações de aminoácidos no lado fetal indicam mecanismo ativo de transporte; esse mecanismo se comporta de tal modo que os aminoácidos neutros são transportados em quantidade que excede muito a necessária ao crescimento intra-uterino: os aminoácidos básicos são em quantidade exatamente as necessárias para esse crescimento.

Alguns estudos referem no retardo de crescimento fetal, diminuição na concentração total de aminoácidos no sangue do cordão, diminuição de treonina, alanina, valina, metionina e arginina, aumento da relação aminoácidos não essenciais/essenciais. Importantes, neste contexto, são os estudos do grupo de Moghisse(1977), que mostraram correlação específica do peso ao nascer com os níveis plasmáticos maternos de lisina, valina, glicina e treonina.

As mais características são o hematócrito elevado, o aumento da massa eritrocitária e, como conseqüência, o aumento da viscosidade sangüínea. A principal causa desse fenômeno parece ser a elevação de eritropoetina consequente à hipóxia crônica, podendo haver também participação de transfusão de sangue placentário para o feto, em condições de hipóxia. As principais conseqüências da hiperviscosidade são alterações pulmonares (que geralmente são correlacionadas com policitemia) e as intestinais, com prejuízo da circulação mesentérica e, conseqüente íleo.

Alterações da coagulação podem seguir-se ao prejuízo da microcirculação, nesses casos.

Outras Características Fisiológicas:

a. Diminuição do glicogênio cardíaco e diminuição da largura das fibras miocárdicas.

b. Em relação à maturação pulmonar, há dados sugerindo sua aceleração e, outros, retardo. Dados importantes mostram aumento da lecitina do líquido amniótico em casos de hipertensão de instalação aguda na gravidez e níveis menores na vigência de hipertensão crônica renovascular. A pré-eclâmpsia materna, classicamente tida como 
fator maturador pulmonar, tem sido reavaliada nesse aspecto, com dados ainda discrepantes, mas que não apoiam, em vários estudos, um efeito maturador.

\section{Muito Cuidado com a fragilidade do recém-nascido de baixo peso}

Principiam com o diagnóstico pré-natal precoce e as medidas de cuidado ao bem-estar fetal. O parto do RNIG decorre com alta freqüência de complicações asfíxicas, com aumento do índice de mortalidade intraparto. A reanimação destes recém-nascidos necessita de cuidados extremos, portanto, com atenção para os sofrimentos mais comuns: asfixia, síndrome de aspiração meconial, hipotermia, policitemia e hipoglicemia. A asfixia e/ou a aspiração de mecônio com freqüência induzem à hipertensão pulmonar persistente; hipocalcemia pós-hipóxica ou conseqüente à administração de bicarbonato não é rara. Na ausência de problema hipóxico ou metabólico grave,

o RNPIG em geral tem um curso neonatal melhor que o recém-nascido pré-termo de peso comparável, tolerando melhor a alimentação e ganhando peso mais rapidamente.

O retardo importante de crescimento fetal indica um estudo o mais detalhado possível da placenta, que muitas vezes pode revelar a etiologia.

A pesquisa cuidadosa de malformações congênitas é fundamental, dada sua relação com o crescimento retardado.

O crescimento e desenvolvimento do RNPIG dependerá, a longo prazo, dos determinantes préconcepcionais, dos problemas ocorridos durante a gestação, da qualidade da assistência perinatal e, talvez, o mais importante fator, das condições intrafamiliares. Analisando-se inicialmente a evolução neonatal de RNPIG, estudos realizados no berçário Anexo à Maternidade do HC-FMUSP durante os anos de 1989, 1990 e 1991, englobando 673 recém-nascidos de baixo peso, fornecem várias informações a respeito da morbimortalidade de tais recém-nascidos. A avaliação da morbidade incluiu vários distúrbios comuns nesta população, tais como asfixia perinatal, hipoglicemia, desconforto respiratório, apnéia, hemorragia intracraniana, policitemia e infecção; destes, os mais freqüentes nos RNPIG foram o desconforto respiratório e as infecções. O desconforto respiratório, mostrou ter grande importância nos RNPIG, em especial o " desconforto respiratório precoce e transitório" e o "desconforto respiratório pós-asfixia". Os recém-nascidos pequenos para a idade gestacional (RNPIG) desproporcionados, bem como aqueles com peso de nascimento inferior a $1500 \mathrm{~g}$ foram os mais afetados por tais distúrbios. Do total de RNPIG estudados, os proporcionados apresentaram maior incidência de crises de apnéia em relação aos desproporcionados. (RAMOS, 2000:154)

As malformações congênitas incidem mais freqüentemente entre os RNPIG. Em idades mais avançadas, as crianças que apresentam malformações, sejam elas ou não prejudiciais em si mesmas, 
estão mais propensas a deficits mentais e neurológicos do que outras de igual peso ao nascer e sem anomalias. A explicação desse fato seria a de que o mesmo fator adverso que no período embrionário causou a anomalia, teria também determinado a alteração do sistema nervoso central em nível celular.

A análise dessa associação em humanos, entretanto, é bastante complexa, em virtude da existência, em países pouco desenvolvidos, de uma associação de fatores que podem dificultar o pleno desenvolvimento das funções cerebrais: condições socioeconômicas baixas e menorsolicitação do meio ambiente. Essas variáveis, associadas à desnutrição intra-uterina, levam ao menor rendimento intelectual da criança e do adulto.

A desnutrição pós-natal também exerce influência muito grande no prolongamento dos efeitos danosos da desnutrição intra-uterina. Trabalhos prospectivos de autores ingleses e norte-americanos sobre crianças de baixo peso, nascidas no final dos anos 40 e início dos anos 50, quando era rotina a restrição alimentar nas primeiras semanas de vida, mostram freqüência alevada de deficits neurológicos.

Estudos realizados nas décadas de 40 e 50, englobando recém-nascidos de peso menor que $1.360 \mathrm{~g}$, revelaram que $50 \%$ dessas crianças estavam em classes especiais em razão de deficits físicos e mentais, $25 \%$ possuíam problemas de aprendizagem e apenas $25 \%$ evoluíram com nível intelectual dentro da normalidade. Os autores relataram ter havido maior incidência de seqüelas em crianças de classes sociais mais baixas. (RAMOS, 2000:154)

Estudos mais recentes sobre o exame neurológico neonatal de RNPIG revelam anormalidades em proporção variável dos casos, sendo importante ressaltar o valor prognóstico desse exame, segundo a maioria dos autores.

Os recém-nascidos estudados na década de 40 e 50 mostraram uma melhora gradativa das anormalidades neurológicas no primeiro ano de vida. A maioria das crianças $(60 \%)$ com distonia severa ou moderada nos primeiros meses de vida, foi considerada normal no final do primeiro ano. $\mathrm{O}$ exame neurológico de outra parte das crianças (20\%), normal com um ano de vida, voltou a anormalidade após os dois anos de vida. Os restantes (20\%), por fim, permaneceram anormais. Um terço das crianças apresentou sinais de hiperatividade e deficit de atenção no exame com três anos.

Essa tendência na anormalização do exame neurológico no decorrer do primeiro ano de vida, também foi constatada por outros autores. Contudo, o acompanhamento dessas crianças até a idade escolar, mostra que a normalização talvez seja aparente, já que uma parte delas apresenta anormalidades neurológicas menores e dificuldades no aprendizado escolar.

Em resumo, pode-se dizer que existem evidências sugerindo maior probabilidade de paralisia cerebral e deficiência mental em recém-nascidos de termo pequeno para a idade gestacional quando comparamos com os recém-nascidos adequados para a idade gestacional. A maioria dos recémnascidos pequenos para a idade gestacional, entretanto, não apresenta seqüelas neurológicas graves e 
tem um nível intelectual normal na idade pré-escolar ou escolar. Deve-se ressaltar, apenas, que o Quociente Intelectual (QI) médio da população pequena para a idade gestacional é, em várias causuísticas, significativamente menor que os do grupo controle.

A asfixia perinatal é um fator muito importante na determinação do prognóstico neurológico dessas crianças, não só pelas lesões do sistema nervoso central decorrentes da encefalopatia hióxicoisquêmica, como também, e principalmente, pela sua maior frequiência nos recém-nascidos pequenos para a idade gestacional..

Pode-se dizer que a diversidade de etiologias do retardo de crescimento fetal parece ser responsável por resultados diversos na avaliação do prognósticos de crianças nascidas com baixo peso. Dos eventos perinatais, a asfixia e a nutrição devem pesar muito na evolução dos recém nascidos de baixo peso.

Por todo esse espectro de possibilidades, este estudo se justifica.

O cenário de estudo é o município de Juazeiro do Norte - CE. É a terceira maior cidade do estado e está localizada no centro do Vale do Cariri, no sul do Ceará. Trata-se de uma região próxima à chapada do Araripe onde viveu a nação indígena Cariris. $\mathrm{O}$ seu povoamento pelos colonizadores em romarias, provocou um aumento da densidade demográfica, em virtude da fertilidade do seu solo.

Trata-se de um santuário popular e religioso, que durante seis meses do ano, peregrinam romeiros em procissões, numa demonstração de fé, esperança e confiança em Deus. Sua característica desenvolvimentista no comércio, na indústria, serviços e urbanismo, a torna um centro de visitação internacional. Em torno da história do Padre Cícero, presente na memória viva do povo, Juazeiro do Norte vê sua população aumentar a cada romaria.

Com uma área de $219 \mathrm{~km}^{2}$, Juazeiro do Norte conta com 7 hospitais, diversos postos de saúde espalhados em pontos estratégicos do município e, é assistido por 36 equipes de Saúde da Família.

O presente trabalho foi realizado no período de Junho a Agosto/2012, no Hospital Maternidade São Lucas, na cidade de Juazeiro do Norte/CE.

Trata-se de um hospital materno-infantil que Realiza mais de 300 partos mensais. Funciona 24 horas por dia, com serviço de neonatologia de pequeno e médio riscos. Possui ótimas instalações cirúrgicas, servindo de referência para municípios vizinhos, aumentando a demanda em épocas de romaria, pois algumas mães romeiras desejam ter seus filhos nascidos na cidade do Padre Cícero.

Diversos estudos têm demonstrado a incidência do baixo peso ao nascer - primeira medida de peso nas primeiras horas após o nascimento - relacionando-o com as condições de morbidade e mortalidade infantil e das condições da gestação (RAMOS, COSTA VAZ e CALLIL, 2000; SILVA, BARBIERI, DAL BÓ, MUCILLO, GOMES, 1991; MARTINS, MELLO, SCOCHI, 2001).

Embora perceba-se uma redução dos índices de baixo peso ao nascer, associados à melhoria das condições sócio-econômicas, de saneamento básico e a uma maior assistência por parte da 
implementação de diversos novos programas nas áreas assistenciais e de saúde, na nossa região, é fato ainda existirem índices significativos de baixo peso ao nascer na cidade de Juazeiro do Norte - CE. Uma parcela significativa da sua população ainda encontra-se submetida a condições precárias de vida e, consequentemente, exposta a fatores de risco.

A escolha do tema justifica-se, levando-se em conta que o baixo peso ao nascer ainda é um problema de saúde pública no Brasil, portanto carente de contribuições que venham a ampliar o conhecimento sobre o assunto. A pesquisa em contextos diferentes ampliam e complementam estudos, a fim de que possamos encontrar saídas realmente eficazes, com relação a melhorias das condições materno-infantil. A idéia é a implementação de uma assistência satisfatória, desde o prénatal, assistência ao parto e puerpério, até programas que fomentem um maior acesso à informação para a população envolvida.

É desolador para nós, profissionais da área de saúde, conviver com este tipo de dificuldade Nascimentos com baixo peso, por conta de carência e muito mais por desinformação das famílias, numa época onde a tecnologia avança a passos largos e o conhecimento encontra-se tão mais acessível.

Mudar esta realidade é uma idéia desafiadora, pois é necessário uma mudança de atitude, de foro íntimo, pois depende de cada um. Alguns compromissos devem ser aceitos como indispensáveis pelos profissionais de saúde: estar sintonizado com novas propostas e experiências, com novas técnicas. Conhecer a realidade de sua comunidade, para praticar uma medicina baseada em evidências e principalmente adotar a ética e o respeito como pressuposto básico à sua prática profissional.

O principal objetivo deste estudo foi caracterizar a totalidade dos nascimentos de baixo peso, ocorridos no Hospital e Maternidade São Lucas - Juazeiro do Norte/CE, entidade pública municipal, no período de junho a agosto/2012, através de um estudo prospectivo e descritivo. Para isso foi necessário também: a) Caracterizar através de um perfil bio-psico-social, as gestantes que realizaram parto de crianças com baixo peso, ou com peso inferior a $2.500 \mathrm{~g}$; b) Identificar a relação entre o número de consultas pré-natais, realizadas pelas mães, objeto de desta pesquisa e os nascimentos de baixo peso; c) Mensurar a população de crianças nascidas com peso menor que 2.500g no Hospital Maternidade São Lucas - Juazeiro do Norte/CE, no período da pesquisa; d) Analisar as variáveis: idade da mãe, estado civil, nível de escolaridade da mãe, profissão da mãe, condição de fumante, número de consultas pré-natais realizadas, tipo de parto a que foi submetida, idade gestacional do recém-nascido, peso do recém-nascido, e se foi a óbito ou não durante a sua permanência no hospital.

Trata-se de um estudo de natureza descritiva, cujas variáveis utilizadas são de natureza quantitativa e qualitativa. A amostra constituiu-se da totalidade de nascidos vivos com baixo peso, isto é, com peso menor que $2.500 \mathrm{~g}$, no período. 
Foram estudados 904 prontuários e outras fontes de pesquisa, durante os meses de junho, julho e agosto do ano 2012, que representam a totalidade dos partos acontecidos neste período, onde desses, passaram a objeto do presente estudo, os 67 recém-nascidos de baixo peso.

Dentre as variáveis levadas em conta neste estudo, estão: idade da mãe, tendo em vista ser esta uma variável importante a ser considerada, na análise da prevalência do baixo peso ao nascer, já que é crescente o número de mães com idades menores que 24 anos; estado civil, pois quando sem um companheiro, que as ajude, as gestantes tendem a ficarem mais vuneráveis física e/ou psicologicamente; nível de escolaridade, pois este parece estar relacionado com a possibilidade um conhecimento maior sobre a necessidade de prevenção de saúde; profissão da mãe, por ser um indicador de condição sócio-econômica, que deve ser levado em conta neste tipo de avaliação; condição de fumante, por ser uma variável nociva à saúde, portanto importante de avaliar sua influência no baixo peso ao nascer das crianças; número de consultas pré-natais realizadas, por ser um importante indicador de prevenção de doenças e problemas durante a gestação; tipo de parto a que foi submetida; idade gestacional, também importante a ser considerada, pois está diretamente relacionada com o peso ao nascer; peso do recém-nascido, variável a ser relacionada com todas as outras e se foi a óbito ou não até o terceiro mês de vida. A presente pesquisa excluiu os natimortos.

As informações foram colhidas à partir de revisão bibliográfica e através dos Prontuários das mães no período da pesquisa; Prontuários do Recém-nascido; Declarações de Nascidos Vivos - MS; Informações contidas nas Fichas Perinatais utilizadas no Programa de Saúde da Família; e de instrumento de coleta de dados elaborado para a finalidade do trabalho.

\section{Resultados e Discussão}

Tabela 1 - Distribuição das idades das mães dos recém-nascidos de baixo peso, no Hospital Maternidade São Lucas, no período de junho a agosto/2012 X Tipo de Parto a que foram submetidas.

\begin{tabular}{l|r|l|r|l}
\hline Idade da Mãe & $\begin{array}{l}\text { Parto } \\
\text { Normal }\end{array}$ & $\mathbf{( \% )}$ & $\begin{array}{l}\text { Parto } \\
\text { Cesárea }\end{array}$ & $\mathbf{( \% )}$ \\
\hline 13 A 16 anos & 4 & 80,00 & 1 & 20,00 \\
\hline 17 a 20 anos & 18 & 90,00 & 2 & 10,00 \\
\hline 21 a 24 anos & 15 & 78,94 & 1 & 12,50 \\
\hline 25 a 28 anos & 7 & 87,50 & 2 & 50,00 \\
\hline 29 a 32 anos & 2 & 50,00 & 3 & 33,33 \\
\hline 33 a 36 anos & 6 & 66,67 & - & - \\
\hline 37 a 40 anos & 1 & 100,0 & 1 & 100,0 \\
\hline$>40$ anos & - & - & $\mathbf{1 4}$ & $\mathbf{2 0 , 8 9}$ \\
\hline TOTAL.......... & $\mathbf{5 3}$ & $\mathbf{7 9 , 1 1}$ & & \\
\hline
\end{tabular}

Fonte: Prontuários do Hospital Maternidade São Lucas/2012. 
Observou-se uma grande incidência de partos cesáreos, de uma maneira geral. 20,89\% dos partos de crianças de baixo peso são partos cesáreos. A incidência de partos cesáreos foi maior nas faixas de 29 a 30 anos(50\%) e de 33 a 36 anos(33,33).

Diante do aumento do número de cesarianas nos últimos anos, a Secretaria de Assistência à Saúde do Ministério da Saúde (SAS/MS) baixou, desde o ano de 1998, diversas portarias para regular o setor. Dentro da estratégia montada pelo órgão destaca-se a organização dos serviços, com implantação de medidas que estimulam a melhoria da qualidade da assistência, a readequação física e tecnológica das unidades, o apoio aos programas de qualificação de recursos humanos e o incentivo financeiro para o parto normal.

Diante da necessidade de aprimoramento da assistência ao parto normal, a Secretaria fez publicar no Diário Oficial da União (DOU) de 29 de maio de 1998, a portaria MS/GM 2.815, que inclui na tabela do Sistema de Informações Hospitalares do SUS, o procedimento "parto normal sem distocia(sem dificuldade) realizado por enfermeiro obstetra", assim como a analgesia, entre os procedimentos relativos a partos normais, com vistas a compor a remuneração para o anestesista.

A medida representa um estímulo à prática do parto normal, já que amplia as condições para a sua realização. Aos efeitos dessa Portaria se soma o da MS/GM 2.816, de 29 de maio de 1998, que busca interferir drasticamente nas elevadas taxas de cesarianas e de mortalidade materna, esta relacionada, em sua maioria, à qualidade da assistência pré-natal e ao parto (LANNES, 1999).

Tabela 2 - Estado civil X Idade das mães dos recém-nascidos de baixo peso, no Hospital Maternidade São Lucas, no período de junho a agosto/2012.

\begin{tabular}{l|c|c|c}
\hline Idade da Mãe & Solteiras & $\begin{array}{c}\text { Casadas ou em } \\
\text { União estável }\end{array}$ & $\begin{array}{c}\text { Não } \\
\text { Declarou }\end{array}$ \\
\hline 13 A 16 anos & 5 & - & - \\
\hline 17 a 20 anos & 15 & 4 & - \\
\hline 21 a 24 anos & 10 & 9 & 1 \\
\hline 25 a 28 anos & 3 & 4 & - \\
\hline 29 a 32 anos & 3 & 1 & - \\
\hline 33 a 36 anos & 2 & 7 & - \\
\hline 37 a 40 anos & - & 1 & $\mathbf{1}$ \\
\hline > 40 anos & - & 1 & $\mathbf{2 8}$ \\
\hline TOTAL............... & $\mathbf{3 8}$ & & \\
\hline
\end{tabular}

Fonte: Declaração de Nascido Vivo/ MS - Hospital Maternidade São Lucas/2012. 
A maioria das mães declararam ser solteiras e não estar vivendo nenhuma relação conjugal ou estável com companheiro, no momento(56,71\%). 41,79\% são casadas ou vivem em união estável.

Um dos principais objetivos do pré-natal, é acolher a mulher desde o início de sua gravidez, pois trata-se de um período de mudanças físicas e emocionais intenso, onde cada gestante vivencia de forma distinta. Essas transformações podem gerar medos, dúvidas, angústias, fantasias ou simplesmente a curiosidade de saber o que acontece no interior do seu corpo.

Estas reações podem ser intensificadas quando a gestante não tem alguém para compartilhar seus sentimentos. Segundo Ribeiro (1994, 27-29), o contato humano é básico para a saúde emocional. É à partir dele que encontramos a alegria de ser pessoa. Segundo o autor: "O contato me permite olhar para o outro, percebe-lo diferente de mim, maior ou menor que eu, e me motiva a crescer, a procurar minhas possibilidades sozinho e com o outro"

Tabela 3 - Distribuição da escolaridade média das mães dos recémnascidos de baixo peso, no Hospital Maternidade São Lucas, no período de junho a agosto/2012

\begin{tabular}{l|c|c}
\hline $\begin{array}{c}\text { Média de Escolaridade da } \\
\text { Mãe }\end{array}$ & $\mathbf{f}$ & $\mathbf{( \% )}$ \\
\hline Nunca estudou & 8 & 11,94 \\
\hline 1 a 3 anos de estudos & 16 & 23,88 \\
\hline 4 a 7 anos de estudos & 24 & 35,83 \\
\hline 8 a 11 anos de estudos & 17 & 25,37 \\
\hline 12 ou mais anos de estudos & 2 & 2,98 \\
\hline TOTAL ..................... & 67 & 100,00 \\
\hline
\end{tabular}

Fonte: Declaração de Nascido Vivo/ MS - Hospital Maternidade São Lucas/2012.

A baixa escolaridade das mães poderia explicar a baixa média de consultas pré-natal observadas na nossa pesquisa, menos de 3 para cada parto (Tabela 9). A grande maioria das mães, $71,64 \%$ não chegou sequer a completar o primeiro grau e apenas $28,26 \%$ chegou a cursar o segundo grau de forma completa ou incompleta.

A frequiência de toda gestante ao pré-natal é fator primordial para a prevenção e o tratamento precoce de diversas afecções que poderão afetar a integridade do Recém-nascido, além de propiciar, no momento do parto, informações necessárias ao atendimento adequado.

Segundo a Federação Brasileira das Sociedades de Ginecologia e Obstetrícia, em muitas regiões do Brasil, mais de $95 \%$ das grávidas freqüentam o serviço pré-natal, no entanto, a morbidade 
materna e perinatal permanecem altas, refletindo deficiências importantes no atendimento. (FEBRASCO, 2000).

A gestante deve procurar o serviço de pré-natal o mais cedo possível, impreterivelmente dentro do primeiro trimestre, a fim de que toda investigação a respeito da sua saúde seja completada em tempo hábil.

O número total de consultas, preconizado pela Organização Mundial de saúde - OMS, não deve ser inferior a seis. Qualquer número abaixo desta cifra já é considerado como atendimento deficiente. (OMS, 1983).

Tabela 4 - Distribuição das profissões das mães dos recém-nascidos de baixo peso, no Hospital Maternidade São Lucas, no período de junho a agosto/2012

\begin{tabular}{c|c|c}
\hline Profissão da Mãe & $\mathbf{f}$ & $\mathbf{( \% )}$ \\
\hline DO LAR & 60 & 89,55 \\
\hline VENDEDORA & 3 & 4,47 \\
\hline AGRICULTORA & 1 & 1,50 \\
\hline PROFESSORA & 1 & 1,50 \\
\hline NÃO INFORMOU & 2 & 2,98 \\
\hline TOTAL & $\mathbf{6 7}$ & $\mathbf{1 0 0 , 0 0}$ \\
\hline
\end{tabular}

Fonte: Declaração de Nascido Vivo/ MS - Hospital Maternidade São Lucas/2012.

A grande maioria das mães são trabalhadoras do lar, isto é, “donas de casa” (89,55\%), portanto, isto leva-nos a crer que dependem de outros para o sustento seu e de sua família. Observamos na Tabela 2, que apenas 41,79\% são casadas ou vivem em união estável e 56,71\% declararam que são solteiras e não estão vivendo nenhuma relação conjugal no momento, portanto com maiores dificuldades de levar a termo uma gravidez saudável em termos alimentares e/ou emocionais. 
Tabela 5 - Distribuição das idades das mães dos recém-nascidos de baixo peso, no Hospital Maternidade São Lucas, no período de junho a agosto/2012 X condição de fumante

\begin{tabular}{c|c|c|c}
\hline Idade Da Mãe & Fumante & $\begin{array}{c}\text { Não } \\
\text { Fumante }\end{array}$ & Não Declarou \\
\hline 13 A 16 anos & - & 2 & 3 \\
\hline 17 a 20 anos & 6 & 3 & 11 \\
\hline 21 a 24 anos & 8 & 8 & 3 \\
\hline 25 a 28 anos & 4 & 2 & 2 \\
\hline 29 a 32 anos & 1 & 2 & 1 \\
\hline 33 a 36 anos & 3 & 1 & 5 \\
\hline 37 a 40 anos & - & 1 & - \\
\hline > 40 anos & 1 & - & - \\
\hline TOTAL................. & $\mathbf{2 3}$ & $\mathbf{1 9}$ & $\mathbf{2 5}$ \\
\hline
\end{tabular}

Fonte: Fichas perinatais das mães - Programa Saúde da Família - Secretaria de Saúde da Prefeitura Municipal de Juazeiro do Norte/CE.

Das 42 mães que fizeram alguma declaração a respeito da sua condição em relação ao tabaco, $54,77 \%$ das entrevistadas revelaram seu uso constante. A maioria se absteve de revelar a sua condição, tendo em vista ser o cigarro hoje, bastante combatido nos meios sociais.

Fumar durante a gravidez traz sérios riscos. Abortos espontâneos, nascimentos prematuros, bebês de baixo peso, mortes fetais e de recém-nascidos, complicações com a placenta e episódios de hemorragia (sangramento), ocorrem mais freqüentemente quando a mulher grávida fuma. A gestante que fuma apresenta mais complicações durante o parto e têm o dobro de chances de ter um bebê de menor peso e menor comprimento, comparando-se com a grávida que não fuma. Tais agravos são devidos, principalmente, aos efeitos do monóxido de carbono e da nicotina exercidos pelo feto, após a absorção pelo organismo materno. (Cotton, 2002).

Segundo o INCA-MS(2000), um único cigarro fumado por uma gestante é capaz de acelerar, em poucos minutos, os batimentos cardíacos do feto, devido ao efeito da nicotina sobre o seu aparelho cardiovascular. Assim, é fácil imaginar a extensão dos danos causados ao feto, com o uso regular de cigarros, pela gestante. Quando uma mãe fuma durante a gravidez, o bebê também fuma, recebendo substâncias tóxicas do cigarro através da placenta. O fumo diminui a oxigenação do sangue e atrapalha o desenvolvimento da criança. Normalmente filho de mães fumantes apresentam peso e estatura menores. Dentre os principais efeitos do tabaco sobre o feto, estão: atraso no crescimento intrauterino; peso reduzido ao nascer; aumento da mortalidade ao nascer; impacto negativo no desenvolvimento físico e mental da criança; Aumento dos batimentos cardíacos; má irrigação sangüínea da placenta; estatura menor; alterações neurológicas importantes; aumento do risco de aborto espontâneo. 
Os riscos para a gravidez, para o parto e para a criança, não decorrem somente do hábito de fumar da mãe. Quando a gestante é obrigada a viver em ambiente poluído pela fumaça do cigarro, ala absorve substâncias tóxicas da fumaça, que pelo sangue, passa para o feto. Quando a mãe fuma durante a amamentação, a nicotina passa pelo leite e é absorvida pela criança. Segundo o Ministério da Saúde - Coordenação Nacional de Controle do Tabagismo - CONTAPP (2000), há uma maior prevalência de problemas respiratórios (bronquite, pneumonia, bronquiolite), em crianças de zero a um ano de idade que vivem com fumantes, em relação àquelas cujos familiares não fumam. Observase que, quanto maior o número de fumantes no domicílio, maior o percentual de infecções respiratórias, chegando a 50\% nas crianças que vivem com mais de dois fumantes em casa. É portanto fundamental que mulheres evitem o cigarro, quando gestantes.

Tabela 6 - Distribuição das idades das mães dos recém-nascidos de baixo peso, no Hospital Maternidade São Lucas, no período de junho a agosto/2012 X Média de consultas pré-natal X Média de escolaridade das mães.

\begin{tabular}{l|c|c|c} 
Idade Da Mãe & $\begin{array}{c}\text { Total de } \\
\text { Mães }\end{array}$ & $\begin{array}{c}\text { Média de } \\
\text { Consultas } \\
\text { Pré-Natais }\end{array}$ & $\begin{array}{c}\text { Tempo } \\
\text { Médio de } \\
\text { Escolaridade } \\
\text { (Anos) }\end{array}$ \\
\hline 13 A 16 anos & 5 & 2,00 & 3,0 \\
\hline 17 a 20 anos & 20 & 2,45 & 5,0 \\
\hline 21 a 24 anos & 19 & 2,80 & 6,0 \\
\hline 25 a 28 anos & 8 & 3,25 & 6,5 \\
\hline 29 a 32 anos & 4 & 3,25 & 2,0 \\
\hline 33 a 36 anos & 9 & 4,11 & 5,0 \\
\hline 37 a 40 anos & 1 & 4,00 & 5,5 \\
\hline > 40 anos & 1 & 3,00 & 0,0 \\
\hline Média & & $\mathbf{2 , 7}$ & $\mathbf{4 , 9}$ \\
\hline Ponderada....... & - & &
\end{tabular}

Fonte: Questionário Sócio-Econômico/2012

Observa-se que há uma associação significativa entre a idade e o número médio de consultas pré-natais. Isto é, quanto maior a idade, maior a média de consultas pré-natais.

O tempo médio de escolaridade, associado a uma idade mais avançada parece, de acordo com a tabela acima, favorecer uma maior procura pelo acompanhamento pré-natal. 
Segundo Siqueira (1975), a ocorrência de recém-nascidos pequenos para a idade gestacional pode ser modificada a nível do pré-natal, tendo em vista que a incidência de recém-nascidos de baixo peso é muito maior entre mulheres que não receberam atenção pré-natal.

O pré-natal é a época ideal para a prevenção da morbidade e mortalidade perinatais, uma vez que é possível atuar no sentido de fazer aumentar o peso dos recém-nascidos, não apenas controlando a patologia da gestação (toxemia e hipertensão, por exemplo), mas principalmente através do diagnóstico do estado nutricional da gestante e correção das carências identificadas. O conhecimento do estado nutricional da população gestante é, pois, em saúde materna, de importância fundamental, não só para o diagnóstico como, principalmente para a elaboração de programas de nutrição para gestantes.

Assim fica demonstrada a necessidade de maior ênfase no alcance da assistência, para o contingente de mães menos cultas e/ou com precário acesso à informação. Estas elevam o risco em não freqüentar o pré-natal ou faze-lo de forma precária e incompleta, aumentando as ocorrências desfavoráveis para mãe e filho, por ocasião do nascimento.

Tabela 7 - Distribuição da Idade Gestacional das mães dos recém nascidos de baixo peso, no Hospital Maternidade São Lucas, no período de junho a agosto/2012

\begin{tabular}{l|c|c}
\multicolumn{1}{c|}{ Idade Gestacional } & f & $\mathbf{( \% )}$ \\
\hline $\begin{array}{l}\text { Prematuro } \\
\text { (Menor que 37 semanas) }\end{array}$ & 27 & 40,30 \\
\hline $\begin{array}{l}\text { Maturo } \\
\text { (37 a 41 semanas) }\end{array}$ & 34 & 50,76 \\
\hline $\begin{array}{l}\text { Hipermaturo } \\
\text { (Maior que 41 semanas) }\end{array}$ & 03 & 4,47 \\
\hline NÃO INFORMOU & 03 & 4,47 \\
\hline \multicolumn{1}{c|}{ TOTAL } & $\mathbf{6 7}$ & $\mathbf{1 0 0 , 0 0}$ \\
\hline
\end{tabular}

Fonte: Prontuários do Hospital Maternidade São Lucas/2012.

A duração da gestação é medida à partir do primeiro dia do último período menstrual normal. A idade gestacional é expressa em dias ou semanas completas.

Algumas regiões com características de baixa condição sócio-econômica dificultam uma avaliação precisa da idade gestacional, pelo desconhecimento da data do último período menstrual, 
pela gestante, ou pela informação de datas tidas como impossíveis de ocorrer, ou ainda pela falta de profissionais, o que poderia levar a falta do registro desta informação tão importante.

Observando-se a idade gestacional dos recém-nascidos com baixo peso ao nascer, na nossa pesquisa, constata-se uma grande incidência de prematuros (40,30\%). Segundo Carvalho (2001), os bebês que nascem pré-termo (antes de completarem 37 semanas de gestação, segundo a OMS), possuem maior risco de adoecer e morrer. Doenças vasculares perinatais tais como: hemorragia cerebral e retinopatia da prematuridade; Infecções como a enterocolite necrosante; Distúrbios metabólicos(hipoglicemis); Dificuldades de serem alimentados e baixo vínculo com seus pais, devido ao restritivo horário de visita imposto pelas UTIs neonatais, fazem com que esses bebês tenham mais chance de serem abandonados.

É possível que o alto percentual de recém nascidos com baixo peso ao nascer pré-termos, possa explicar o alto índice de mortalidade observado na nossa pesquisa de 23,86\% (ver tabela 8).

Tabela 8 - Distribuição do Peso-ao-nascer dos recém nascidos de baixo peso, no Hospital Maternidade São Lucas, no período de junho a agosto/2012 X Média de consultas pré-natal das mães

\begin{tabular}{l|c|c}
\hline $\begin{array}{c}\text { Peso ao Nascer } \\
(g)\end{array}$ & $\mathbf{N}^{\mathbf{0}}$ de Crianças & $\begin{array}{c}\text { Média de } \\
\text { Consultas } \\
\text { Pré-Natais }\end{array}$ \\
\hline$>1.100$ & 8 & 1,6 \\
\hline $1.100-1.299$ & 3 & 1,0 \\
\hline $1300-1.499$ & 1 & 0,0 \\
\hline $1.500-1.699$ & 3 & 3,0 \\
\hline $1.700-1.899$ & 3 & 2,3 \\
\hline $1.900-2.099$ & 7 & 2,8 \\
\hline $2.100-2.299$ & 16 & 3,5 \\
\hline $2.300-2.499$ & 26 & 3,4 \\
\hline Total................. & $\mathbf{6 7}$ & - \\
\hline
\end{tabular}

Fonte: Prontuários das crianças e das mães do Hospital Maternidade São Lucas

Observa-se uma associação significativa entre a freqüência à assistência do Pré natal e o peso-ao-nascer. Os resultados sugerem que quanto maior a média de consultas pré-natal, maior o pesoao-nascer. Ao que a pesquisa indica, uma prevenção à partir das consultas pré-natais, diminuiria os riscos de nascimentos de baixo peso. Avila-Rosas et al (1988) afirmam que a carência de controle prénatal aumenta em 18 vezes o risco de nascimentos de baixo peso, sendo um indicador útil para diferenciar aqueles que não apresentam baixo peso-ao-nascer daqueles que o apresentam. 
Tabela 9 - Distribuição das Idades das mães dos recém-nascidos de baixo peso, no Hospital Maternidade São Lucas, no período de junho a agosto/2012 X Número de Óbitos.

\begin{tabular}{l|c|c|c|c}
\hline \multicolumn{1}{|c|}{ Idade da Mãe } & $\mathbf{N}^{\mathbf{0}}$ de Mães & $\begin{array}{c}\text { Total de } \\
\text { Crianças que } \\
\text { Não Foram a } \\
\text { Óbito }\end{array}$ & $\mathbf{N}^{\mathbf{0}}$ de Óbitos & $\begin{array}{c}\text { Percentual de } \\
\text { Óbitos, } \\
\text { Relativos a } \\
\text { População de } \\
\text { Nascidos } \\
\text { Vivos }\end{array}$ \\
\hline 13 A 16 anos & 5 & 2 & 3 & 4,47 \\
\hline 17 a 20 anos & 20 & 14 & 6 & 8,95 \\
\hline 21 a 24 anos & 19 & 14 & 5 & 7,46 \\
\hline 25 a 28 anos & 8 & 6 & 2 & 2,98 \\
\hline 29 a 32 anos & 4 & 4 & - & - \\
\hline 33 a 36 anos & 9 & 9 & - & - \\
\hline 37 a 40 anos & 1 & 1 & - & - \\
\hline > 40 anos & 1 & 1 & - & $\mathbf{2 3 , 8 6}$ \\
\hline TOTAL........... & $\mathbf{6 7}$ & $\mathbf{5 1}$ & $\mathbf{1 6}$ & \\
\hline
\end{tabular}

Fonte: Prontuários do Hospital Maternidade São Lucas/2012.

A mortalidade de bebês nascidos de baixo peso apresentou-se muito grande entre mães jovens, principalmente na faixa de 13 a 16 anos, onde a mortalidade chegou a $60 \%$ dos nascidos vivos com baixo peso. Nas faixas de 17 a 20 e 21 a 24 , a mortalidade chegou a $30 \%$ e 26,31\%, respectivamente. Ainda considerada alta para os padrões da OMS. Não aconteceu nenhum óbito nos casos de mulheres com idade superior a 29 anos.

\section{Considerações Finais e Recomendações}

Pelo exposto nas tabelas e considerando o contexto baseado nos estudos investigativos na literatura especializada, podemos tecer as seguintes considerações:

1. Mesmo que os estudos tenham revelado um descréscimo da mortalidade infantil no Brasil, tem-se observado que os agravos ao recém-nascido continuam ocorrendo na cidade de Juazeiro do Norte, onde a condição das crianças de baixo peso ao nascer, ainda não atingiu uma taxa aceitável. A mortalidade de bebês nascidos de baixo peso, apresentou-se muito significativa entre mães jovens, principalmente na faixa de 13 a 16 anos, onde chegou a $60 \%$. Nas faixas etárias de 17 a 20 e 21 a 24 anos, a mortalidade infantil dos recém-nascidos vivos com baixo peso ao nascer, chegou a $30 \%$ e $26,31 \%$ respectivamente. Estes índices são 
considerados altos pela OMS. Neste particular, por sua contribuição com a morbidade e mortalidade infantil, notadamente a perinatal, torna-se um problema de Saúde Pública. Portanto torna-se urgente um planejamento que venha a contemplar a informação para este contingente. As gestantes constituem o foco principal do processo de educação para a saúde, porém não se pode deixar de atuar, também, entre os companheiros e familiares. A posição do homem-pai na sociedade está mudando, tanto quanto os papéis tradicionalmente atribuídos às mulheres. É necessário que o setor Saúde esteja aberto para as mudanças sociais e cumpra, de maneira mais ampla o seu papel de educador e promotor da saúde;

2. As crianças pertencentes às famílias de baixo nível sócio-econômico-cultural (baixa escolaridade das mães- $11,94 \%$ nunca estudou e $71,64 \%$ não chegou sequer a completar o primeiro grau; sua situação civil- $56,71 \%$ declararam ser solteiras e não estar vivendo nenhuma relação estável com companheiro, no momento da pesquisa - e profissional - a grande maioria, $89,55 \%$ são trabalhadoras do lar, não exercendo nenhuma atividade remunerada; dentre outras), estão expostas a riscos de natureza ;diversas: biológico e ambiental, riscos sociais e exposição a ambientes empobrecidos. Assim requerem auxílio social e apoio emocional, que podem advir de programas de visitas domiciliares, através da atuação de equipes multiprofissionais, dentre outras medidas que venham a contribuir para a melhoria da informação sobre saúde, e para a redução dos índices de mortalidade infantil na nossa região;

3. As intervenções combinadas entre hospital e domicílio podem ser uma alternativa importante, por iniciarem as orientações, estimulando uma maior participação dos pais, nos cuidados não especializados com o bebê, na unidade de internação, de forma a prosseguirem com visitas domiciliares após a alta, oferecendo continuidade e possibilidade de benefícios para o adequado desenvolvimento infantil a longo prazo;

4. Os estudos revelam e a pesquisa constatou que, a melhoria da assistência primária, no momento do pré-natal, parto e período neonatal, contribuem para a melhoria das condições de nascimento e sobrevivência da população infantil. Observou-se também que uma associação positiva entre peso ao nascer e o número médio de consultas pré-natais realizadas pelas mães. Os resultados sugerem que quanto maior a frequiência ao pré-natal, maior o peso ao nascer. Propomos pois, que, na cidade de Juazeiro do Norte/CE, haja uma intensificação da atuação primária, no tocante à saúde da mulher e da criança. Que a humanização da assistência obstétrica seja uma realidade no Hospital Maternidade São Lucas, visando, não só a promoção do parto e do nascimento saudáveis, como também, a prevenção da morbi-mortalidade materna e perinatal. 
Que o parto seja resgatado como o momento do nascimento, respeitando-se todos os seus significados, devolvendo-se à mulher o seu direito de ser mãe de forma mais humanizada e segura.

\section{Referências}

AVILA-ROSAS, Héctor; CASANUEVA, Esther; BARREIRA, Audelia; CRUZ, Isabel \& ROJO, Maria Cavadonga, Alguns determinantes biológicos y sociales del peso al nacer. Salud Pública del México, 30(1):47-53; Enero-Febrero, 1988;

ARRUDA, Ilma Kruze Grande, Prevalência da anemia em gestantes de baixa renda: algumas variáveis associadas e sua repercusssão no recém-nascido. Recife: Tese de Mestradoda Universidade Federal de Pernambuco, 1990, p.41-99;

AVERY, Gordon B., Neonatologia: Fisiopatologia e cuidados do Recém-nascido, São Paulo: Artes Médicas, 1978;

BATTAGLIA F.C., LUBCHENCO L.O., A pratical classifications of newborn infants by weight and gestacional age. J. Pediatr. 71:159, 1967.

BITTAR, R. E., Crescimento intra-uterino retardado. IN: Zugaib, M.(ed.) Medicina Fetal, 2 ed., São Paulo, Atheneu, 1998;

CARNEIRO, Regina Lúcia W. Soares, Mortalidade neonatal segundo o peso-ao-nascer, idade materna e sexo. Recife: Tese de Mestrado, Universidade Federal de Pernambuco, 1989, p.52-54;

CARVALHO, Marcus Renato de, "Amamentação on line", Lei do Prematuro, Faculdade de Medicina - IBFAN, Rio, 2001, < http://www.aleitamento.org.br/leiprematuro.htm > (30/12/2001);

COTTON, Janine, Gravidez e fumo, 2002 < http://www.taps.org.br/minfantil.htm > (01/02/2002);

COUTINHO, Sônia Bechara. Mortalidade neonatal em 5 maternidades da cidade do Recife, 1994. Recife, Relatório final de pesquisa apresentado ao UNICEF, 1996, p.47-48;

FEBRASCO - FEDERAÇÃO BRASILEIRA DAS SOCIEDADES DE GINECOLOGIA E OBSTETRÍCIA, Assistência Pré-natal, 2000, p.30-31.;

FORATTINI, Oswaldo Paulo. Epidemiologia geral. São Paulo: Artes médicas, 2 ed., 1996, p.135141 ;

FUNDAÇÃO NACIONAL DE SAÚDE - COORDENAÇÃO REGIONAL DE PERNAMBUCO. INSTITUTO MATERNO INFANTIL DE PERNAMBUCO (IMIP), INSTITUTO NACIONAL DE ALIMENTAÇÃO E NUTRIÇÃO. 4 - Peso-ao-nascer. 20:6., agosto, 1995;

HERANI, Maria Luiza Gugliano, Normas para a apresentação de Dissertações e Teses. São Paulo:BIREME - Organização Pan-Americana de Saúde, Organização Mundial de Saúde, 1990; 
JORGE, Salim Moyses \& GONÇALVES, Arthur Lopes, Avaliação da idade gestacional pelo exame clínico do recém nascido. IN ALVES FILHO, Navantino \& CORRÊA, Mário Dias. Manual de Perinatologia. Medisi - Rio de Janeiro: Médica e Científica, 1990, p. 497-512;

KAHHALE, Soubhi \& KWANG, Wu Nan, Seção I - O feto - Mortalidade perinatal. IN Pediatria Básica [Coordenador geral Eduardo Marcondes], 8ed., São Paulo: SARVIER, 1991, 1v.,p.255;

LANNES, Rogério, Assistência Perinatal e neonatal no Brasil: Um desafio pra os serviços de saúde, Uma estratégia de Regulação, Revista TEMA, No. 17, fevereiro, 1999, p.22;

LIMA, Roberto Teixeira. Peso-ao-nascer no município de João Pessoa/PB - Estudo comparativo entre dados primários e secundários. Recife: Tese de Mestrado da Universidade Federal de Pernambuco, 1995;

LIN, C. C.; EVANS, M. L., eds Intrauterine Growth Retardation, New York, Mc Grow Hill, 1984;

LUCENA, Líbia; LIMA, Roberto T.; MARINO, Wanda T., O baixo peso ao nascer ainda é um problema de saúde pública no Brasil?, Revista de Pediatria, vol. 16, No.01, março, 1998, p.15-25;

MARCONDES, Eduardo, Pediatria básica, 5 ed., São Paulo: Sarvier, 1975;

MARTINS, Danielle C., Mello, Débora F. de, SCOCHI, Carmem G.S., Crianças prematuras e de baixo nível socioeconômico: uma revisão da literatura, Revista PEDIATRIA MODERNA, Vol XXXVII, No. 9, setembro de 2001, p. 452-459;

MINISTÉRIO DA SAÚDE. SECRETARIA NACIONAL DE PROGRAMAS ESPECIAIS DE SAÚDE. DIVISÃO NACIONAL DE SAÚDE MATERNO-INFANTIL \& INSTITUTO NACIONAL DE ASSISTÊNCIA MÉDICA DA PREVIDÊNCIA SOCIAL, Assistência Pré-natal. Ministério da Saúde, Secretaria Nacional de Programas Especiais de Saúde, Divisão Nacional de Saúde MaternoInfantil \& Instituto Nacional de Assistência Médica da Previdência Social. Brasília, Centro de Documentação do Ministério da Saúde, 1988, p 17-31;

MINISTÉRIO DA SAÚDE, INSTITUTO NACIONAL DE CÂNCER, COORDENAÇÃO NACIONAL DE CONTROLE DE TABAGISMO - CONTAPP, Falando sobre tabagismo, Rio de Janeiro, 1996;

MINISTÉRIO DA SAÚDE, INSTITUTO NACIONAL DE CÂNCER - COORDENAÇÃO NACIONAL DE CONTROLE DE TABAGISMO - CONTAPP, INCA - INSTITUTO NACIONAL DO CÂNCER "Como implantar um programa de tabagismo", O Fumo e a gravidez, $2000<$ http://www.inca.org/prevenção/tabagismo/tabgravid/html > (30/12/2001).

MOGHISSI, K. S., Relationship of maternal aminoacids and proteins to infant grouth and mental development. IN: MOGHISSI K. S., EVANS, T.N., eds Nutritional impacts on women Hagerstown, Hrper \& Row, 1977;

MONTEIRO, Mário F.G., Baixo peso ao nascer. IN Perfil estatístico de crianças e mães no Brasil: aspectos de saúde e nutrição de crianças no Brasil 1989. Rio de Janeiro: IBGE/UNICEF, Departamento de Estatística e Indicadores Sociais, 1992; 
NAISMITH D. J., Diet during pregnancy. A rational for prescription. IN: Dobbing J. ed. Maternal Nutrition in pregnancy-eating for two?, Londom, Academic Press, 1981;

NUSSBAUMER, Frederico W.J., Recém-nascidos de peso baixo ao nascer, Revista Clínica Pediátrica, São Paulo, volume V, No. 4 - abril/maio/junho, 1981, p.10-15;

OLIVEIRA, Luiz Antônio P., A mortalidade infantil recente e a dinâmica social. IN Perfil estatístico de crianças e mães no Brasil - Mortalidade infantil e saúde na década de 80 . Rio de Janeiro: IBGE/UNICEF, Departamento de Estatística e Indicadores Sociais, 1989;

ORGANIZACION MUNDIAL DE LA SALUD, Medicion del cambio del estado nutricional directrices para evaluar el efecto nutricional de programas de alimentación suplementaria destinados a grupos vulnerabiles. Genebra: 1983, p. 1-14;

PEREIRA, Rute Cândida Pereira, Anemia em parturientes da Maternidade Prof. Monteiro de Moraes e Peso-ao-nascer: Impacto de condicionantes macro e micro-estruturais. Recife, Tese de Mestrado da Universidade Federal de Pernambuco, 1997, p.17-26;

POLANI, P. E., Chromosomal and other genetical influences on birth weight variation. IN: Size at Birth (Ciba Foundation Symmposium 27) Amsterdam, Associated Scientific Publishers, 1974;

RAMOS, José Lauro A, VAZ; Flávio Adolfo Costa; CALIL, Valdenise M L Tuma, O recém nascido pequeno para a idade gestacional, Revista PEDIATRIA MODERNA, Vol XXXVI, Edição especial, junho de 2000, p. 153-164;

RASGONESI, S. M. A., Contribuição ao estudo do crescimento intra-uterino retardado. Dissertação de Mestrado, Universidade Federal de São Paulo, 1993;

RAMOS, J. L. A., A avaliação do crescimento intre-uterino por medidas antropométricas do recém-nascido. Tese de Doutorado, faculdade de Medicina da USP, 1983;

RIBEIRO, Jorge Ponciano, Gestalt Terapia: O processo grupal, uma abordagem fenomenológica da teoria de campo e holística, São Paulo: Summus, 1994;

ROCHA, João de Albuquerque, Baixo Peso ao Nascer - peso insuficiente e peso adequado. Recife: Tese para Professor Titular de Pediatria, Universidade Federal de Pernambuco, 1985;

RODRIGUEZ, Odalis T. Sinisterra; SZARFARC, Sophia Corbluth \& BENICIO, Maria Helena d`Aquino, Anemia e desnutrição maternas e sua relação com o peso ao nascer. Rev. Saúde Pública, São Paulo, 25(3): p.193-197, Junho, 1991;

ROUQUAYROL, M. Zélia, Epidemiologia \& Saúde, 3ed. Rio de Janeiro: Medisi, 1988, p.169-203;

SERRANO, Carlos V. \& PUFFER, Ruth R., Datos del peso al nascer y de la mortalidad en hospitales utilizados como indicadores de los problemas de salud en la infancia. Bol. Of. Sanit. Panam., Washington, LXXVIII(2):93-119, Febrero, 1975;

SILVA, Antônio A M; BARBIERI, Marco Antônio; BETILOL, Heloísa; DAL BÓ, Creuza M R, MUCILLO, Gérson; GOMES, Uillho Antônio, Saúde perinatal: baixo peso e classe social, Revista Saúde Pública, São Paulo, 25(2): 87-95, 1991.; 
SIMÕES, Celso Cardoso, Mortalidade infantil e saúde na década de 80. IN IBGE/UNICEF Perfil estatístico de crianças e mães no Brasil - Mortalidade infantil e saúde na década de 80 . Rio de Janeiro: 1989, p. 9-13;

SIQUEIRA, A. A. F. de, et al., Influência da altura e ganho de peso maternos e de idade gestacinal sobre o peso do recém-nascido: estudo de três grupos de gestantes normais, Revista Saúde Pública, São Paulo, No. 9, p. 331-342, 1975;

SOUTO JÚNIOR, José Veloso e RIBEIRO, Maria Aparecida A., "Tabagismo: O perigoso hábito do fumo", Fumo e gravidez, 2000, < http://www.nib.unicamp.br (30/12/2001);

SPALLICI, M.D.B. et al, Estudo de algumas variáveis maternas, relacionadas com a prematuridade no Hospital Universitário de São Paulo, Rev. Med. HU-USP, v.10, n.1, jan-jun, 2000. < http://www.latina.obgyn.net/pr/articles/estudode.htm > (12/03/2002).

VAZ, Flávio Adolfo Costa (Coord.), Cuidados ao recém-nascido normal e patológico, São Paulo: Sarvier, 1989;

Paulo: Atheneu, 1993;

Assistência à gestante de alto risco e ao recém-nascido nas primeiras horas, São

VIEIRA, Pe. Antônio. Roteiro Lírico e místico sobre Juazeiro do Norte, Fortaleza: Editora Imprensa Oficial do Ceará - IOCE, 1988;

WIDDOWSON, E. M., The demands of the fetal and maternal tissues for nutrition, and bearing of these needs of the mother to "eat for two". IN: Dobbing J. ed. Maternal nutrition in pregnancy-eating for two?. Londom, Academic Press, 1981;

ZISMAN, Meraldo, Peso ao nascer: Evolução, distribuição e fatores de variações em amostras de diferentes condições sociais do Recife. Recife: Tese para Professor Titular, Universidade Federal de Pernambuco, 1985, p.184-187.

Como citar este artigo (Formato ISO):

ARAÚJO, Graciella M.; BEZERRA, Martha M.M; MARANHÃO, Thércia L.G. Considerações sobre neonatos de baixo peso ao nascer. Id on Line Revista de Psicologia, Julho de 2014, vol.8, n.23, p. 26-56. ISSN 19811179. 